
\title{
$\angle$ Research Square \\ Hospital Managers Skills Required and Onward Challenges: A Qualitative Study
}

Farideh Moradi

Kermanshah University of Medical Sciences

Arash Ziapour

Kermanshah University of Medical Sciences

Jaffar Abbas

Shanghai Jiao Tong University School of Medicine

Nadya Baharirad

Kermanshah University of Medical Sciences

ali soroush ( $\square$ alisoroush569@gmail.com )

Kermanshah University of Medical Sciences https://orcid.org/0000-0002-9485-9662

Research

Keywords: Hospital managements, Challenges, Managers skills

Posted Date: February 17th, 2020

DOI: https://doi.org/10.21203/rs.2.23432/v1

License: (9) This work is licensed under a Creative Commons Attribution 4.0 International License.

Read Full License

Version of Record: A version of this preprint was published at Journal of Education and Health Promotion on January 1st, 2020. See the published version at https://doi.org/10.4103/jehp.jehp_171_20. 


\section{Abstract}

Background: The qualification of managers in terms of management skills is one of the most important factors in the continuous success of each organization and utilizing such skills can have a positive contribution in the effectiveness of the organization while improving the performance of the employees in line with the objectives and goals of the organization. The main objective of the current study was to explore the necessary skills and the challenges of hospital managers from the point of view of managers at different levels of a hospital.

Methods: This study is a qualitative one where the statistical population includes the mid-level and senior-level managers of the hospital. The sample size was 22 individuals. The interviews were analyzed by a MAXQDA software application after transcription. Results This study includes 5 main themes and 15 secondary themes. The strategic skill, the perceptive skill, the human relation skill, work experience, and personal characteristics were among the skills necessary for hospital managers. Some of the challenges facing the hospital managers included rapid changes in the policies, the limitations of financial resources, and lack of proportion between the educational and occupational spheres.

Conclusion: Because of their existential philosophy and differences with other service sectors, managing hospitals poses a particular sensitivity. In this regard, the role of the hospital manager is very important. Therefore, in order to meet the satisfaction of those receiving services, decision makers, and policy makers must think twice when selecting and appointing hospital managers and evaluate and appraise this group in terms of abilities and skills necessary for managing such an important service section.

\section{Background}

Hospitals are among the main components of the healthcare system in any country and amending the healthcare system will not be possible without paying attention to these centers and improving their performance. These centers, as the most important healthcare institutions at the third level of providing healthcare services, play a major role in improving the health state of the country and providing services [1]. In the current century, hospital managers play a major role in the survival as well as the efficiency and productivity of this important institution and in this regard, they have ethical and legal responsibility [2]. Hospital managers play a major role in advancing the goals of the healthcare system, supervising and directing human resources, as well as ensuring the quality of the care and the security of hospitals. Ultimately, the goal of this group is to maintain and provide health of the community members [3]. In 2009, the National Committee of the Eastern Mediterranean of the World Health Organization emphasized the importance of management and leadership in hospitals [4]. The qualification of managers in terms of management skills is one of the most important factors in the continuous success of each organization and utilizing such skills can have a positive contribution in the effectiveness of the organization while improving the performance of the employees in line with the objectives and goals of the organization. Lack of sufficient awareness of managers of these skills and their utilization can be an inhibiting factor in this regard and reduce the overall success of the organization as a whole. In general, it 
is difficult to imagine a successful manager in modern organization without having basic skills [5]. Manager qualifications refer to the knowledge and skills required for a manager to perform his/her responsibilities. In other words, management qualification is defined as "the behavior of a manager in performing his/her management duties and realizing a positive level of work performance, which shows his/her motivation, personal characteristics, skills, self-image, social role, knowledge, experience, and accountability" [6]. Therefore, qualifications mean unique characteristics such as knowledge, skill, and capability, which are sufficient for affecting the ability of the individual for producing excellent performance. The results of the study Lin, Battilana, Dignam, Müller indicate the effects of management skills and qualifications on factors such as effective leadership, personal and organizational performance, organizational spirit, and the effectiveness of managers [7-10]. The reports published by the Ministry of Health, Treatment and Medical Education in recent years indicate that about 90 percent of the managers of hospitals in Iran do not have any management expertise in the field of healthcare, which reduces the productivity of hospitals [11]. Healthcare organizations, particularly hospitals, are constantly facing challenges from variable internal and external forces including changes in technology, changes in the healthcare market, changes in economic conditions, and amendments and corrections of the healthcare system. These advances and changes challenge the capability and ability of managers in the organization and force them to revisit and reevaluate the qualifications and skills needed by the managers [2]. The majority of efforts for increasing the capacities of the healthcare system have focused on increasing general medical and healthcare skills and there has been less attention to the development of hospital managers despite their major role in improving the performance and the quality of the healthcare system [12]. Considering the issues above and since one of the important and basic competitive edges in the current competitive environment is the aspect of management, identifying the developmental needs is the first important step and a key process in a systematic management development process. Therefore, this study has been carried out in order to identify the needs of the management skill development of the managers of educational hospitals under the supervision of the Medical University of Kermanshah.

\section{Methods}

\section{Study design}

With regards to the process of executing the investigation, this study is a cross-sectional qualitative study (content analysis). The deep interviews were performed with 22 managers (senior and middle managers) of educational hospitals of Kermanshah City who had master's or PhD degrees, with at least 5 years of experience in management and with an age between 35 and 50 years in the hospitals. The interviews were performed by two female researchers who had master's degrees and were experienced in performing interviews. Before performing the main interviews, pilot interviews were performed with 8 colleagues who had executive experience in hospitals. Four of the managers couldn't participate in the study because they were too busy. After selecting the participants, they were contacted by phone and after explaining the objectives of the study, they were invited to participate in the study on a volunteering basis. When each 
participant expressed their willingness to participate in the study, a date was set for a face-to-face meeting based on their choice of date. At the interview meeting, the guidelines of the interview were presented to each of the participants to study and sign. Each interview lasted for about 60 minutes. During the interview, the entire session was recorded. Then, with the help of one of the members of the research team, who wasn't in contact with the participants, the exact verbatim transcriptions of the interviews were made and finally, the data analysis was performed using MAXQDA software application. The written content of the interviews and the initial extracted codes were presented to the participants to review and confirm. Moreover, in order to ensure the reliability of the results of the study, various methods including soliciting the help of two other colleagues and one of the experts familiar with qualitative research, sending the written content of the interviews and the extracted codes to each of the participants to review and confirm, applying concurrent analysis through collecting data and transcribing the text of the interviews by one of the members of the research team were utilized.

\section{Results}

Among the 22 participants in this study, 21 individuals (91.7 percent) were male while 1 individual (3.8 percent) was female. The average length of the interviews was 24 minutes. The findings of the study are presented in two sections. In the first section, the skills and capabilities required by the managers are explored while in the second section, the challenges facing the managers are presented. The skills required for hospital managers are categorized into 5 main themes and 15 secondary themes (Table1). The challenges reported by the managers are categorized into 3 main themes and 7 secondary themes (Table2).

Table 1 The mentioned main and sub- themes related to the hospital managers skills required 
Environmental analysis

Strategic Skill

The power of futurism

External environment analysis

Diagnosing the position of individual operations in the organization Perceptive Skill

Prioritizing hospital problems

Problem solving process

Decision making in unstable situations

Participation and teamwork

Human Relations Skill

Communication with others

Management background

Experience in management

Work Experience

Motivation and interest

Personal Characteristic

Management knowledge

Self-confidence and courage in decision making

self-management

Continuous individual development

Table 2 The main and sub-themes related to the hospital managers onward challenges

Sub theme

- Quick change of policies

- $\quad$ Lack of transparent rules

- Human resource constraints

- Financial resource constraints

- Week resource management

- Incompatibility of field of study and field of work Education

- Lack of attention to prioritization of training topics
Theme

Policies and Regulations

Resources and Facilities

Page 5/14 


\section{The Skills and Qualifications Required by Hospital Managers}

The skill of human relations: the skill of human relations refers to the ability and capability with regards to creating an environment for coordination and collaboration and delegating tasks to others, having effective activities as a group member, understanding the motivations of individuals and affecting their behaviors. From the point of view of the majority of the participants, the human relations skill and the capability to interact with others are among the most important and basic skills required by managers since this skill is the key to the success of the hospital manager. "I think that the key to the success of a good manager is his/her ability to establish good relations with his/her colleagues and subordinates" [I5]. "In fact, a good manager must like his/her employees and he/she should have great encounters with them and be able to establish good relations with them" [1-12].

Work experience: one of the qualifications emphasized by participants as necessary for the success of a manager was management experience where the experience of working in the hospital and having experience in managerial positions were among the cases mentioned. "Having the necessary knowledge and expertise in the field of management will not be enough; rather, the manager must also have experience working in a hospital to understand the nuances of various issues" [1-21]. "In my opinion, one of the qualifications necessary for becoming a manager must be a work experience of at least five years in a hospital; it shouldn't be the case that after getting a degree, they get the management posts easily" [I14].

Perceptive skill: the perceptive skill is one of the skills necessary for a successful manager. Issues that must be focused on in this regard include the manager's discretion based on the matching of each employee with his/her position, prioritizing the problems of the hospital, and selecting the proper process for resolving or mitigating these problems. "The manager must be able to determine the position of individuals based on their expertise and experience" [1-3]. "The manager must prioritize the problems of the hospital. It shouldn't be the case that the manager forgets about the bonuses of the employees but goes around expanding the hospital wards or decorating the departments" [1-2].

Having strategic skills: having a strategic long-term vision and having the ability to predict future were among the items considered by the participants as the skills and abilities of the hospital manager. "A successful manager must be capable of guiding the organization towards proper long-term perspectives and he/she must lead the hospital in a way that it gets better year after year" [1-11]. "A good manager must have a long-term vision and he/she must be able to have a suitable analysis of the internalities and externalities of the organization and base his/her plans on these issues" [1-18].

Personal characteristics: some of the participants reported that people who apply to become the manager of a hospital must have specific personal characteristics such as being interested in acquiring that managerial position. Being motivated to work, having self-esteem, and having sufficient information about the hospital environment were among the other items mentions. "Being motivated and interested is 
very important and necessary for a manager. An unmotivated manager will make the majority of employees lose their motivations as well" [1-7]. "The manager must be decisive in his/her decision making and he/she should be frank with everybody. He/she should see subordinates as friends or acquaintances whose mistakes you should neglect" [I-2]. "The manager must be capable of adapting to modern issues and he/she must be updated. His/her thoughts must also be up to date" [I-8].

\subsection{Challenges Facing Hospital Managers}

1. Policies and Regulations: one of the challenges mentioned by the interviewees was the issue of the rapid changes in the policies and regulations of the Ministry of Health. In this regard, one of the participants says "the policies of the Ministry of Health change rapidly and quickly, and when you are still trying to become familiar with a policy and learn what it is all about, suddenly they change the policy" [l-10]. With regards to the lack of clear regulations, one of the interviewees said: "regulations and bureaucracies restrict the freedom of the managers and in fact tie his/her hands since he/she cannot change any part of them" [1-22].

2. Resources and assets: shortage of resources and financial and human assets was among the challenges mentioned by the interviewees. In this regard, interviewee 17 , as one of the senior managers, says "hospitals are facing a shortage of resources, particularly with regards to the number of nurses. We are also facing problems related to money and the budget. For instance, when a piece of equipment breaks down, there is no money to repair it. Insurance companies, on the other hand, do not have any money to give us" [1-13]. "At the moment, the main concern of the managers is about the shortages" [1-10].

3. Education: weak education and lack of fit between the education and degrees of individuals and their occupational area were among the challenges mentioned by the managers. In this regard, interviewee 10 said "there is no relationship between the university major of the managers and their occupational area. For instance, people who have studied hospital management must become hospital managers because they have the required expertise, but we don't see that in practice" [1-6]. "Nowadays we see that the majority of physicians are hospital managers and if you look closer, they don't even know what management means" [1-4].

\section{Discussion}

In this study, the skills needed for hospital managers and the challenges they are facing were identified. Based on the results obtained from the study, the skill of human relations is one of the skills needed by hospital managers. The results from Pillay show that managing individuals and human skills are the most important skill for healthcare managers [13]. Moreover, Majid and AHAN shows a significant relationship between the human skill of managers and the motivation of the employees $[14,15]$. The results of a national survey in the US show that the most important skill and qualification needed for nursing managers was effective and influential relations [16]. Other studies also emphasize the importance of the skill of relations for the managers of healthcare centers, particularly hospitals $[17,18]$. The study carried out by Khadka emphasizes the importance of communicative skills for hospital 
managers and the authors suggest that leadership and communication skills are the most important competitive factors among hospital managers [19]. The results from Stefl show that relations management and communications, which include communicative, facilitative, and negotiating skills, are among the important skills for a manager [20]. Furthermore, the results from Kalargyrou indicate the importance of the skill of human relations among the skills of the managers. The results of these studies are in line with the results of the current study [21]. The skills of the managers lead to the increase in their acceptance and appeal among the employees, which results in reduced stress and improved performance of the employees [1,22-25]. Kebede show that training hospital managers based on improving their managerial skills results in a significant improvement in the performance of healthcare systems [26]. Therefore, it is suggested that the evaluation of the relations of the managers with the employees be performed regularly and it is suggested that workshops be held for managers about the methods of proper interaction with the employees including sympathizing with the employees and effective listening to them. Managerial knowledge was one of the items mentioned in the majority of the interviews. The results of a study on hospitals supervised by the Medical University of Tehran show that the field of managerial knowledge is divided into four categories, i.e. planning, organizing, control, and leadership. Among these, leadership has the highest priority from the point of view of middle managers of hospitals [27]. Despite this fact, in their study, Khadka point out that management knowledge is less important. However, their study was carried out in private and public hospitals; while 59 percent of the participating managers had no prior management education or training [19]. A study by Rivkani shows that while 70 percent of the hospital managers have passed the training course for managing hospital affairs, not all of them possessed the proper managerial knowledge and experience [28]. Another result of this study was the focus on the strategic and long-term vision as one of the skills of the hospital managers. Creating and developing a strategic mindset is one of the requirements of the field of management and this type of mindset is necessary and critical for all the organizational levels, particularly for the senior management [29]. Hospitals as the most important and most complex organizations providing healthcare require systemic and systematic mindsets more than any other organization. The systemic mindset is a conceptual framework for solving problems, which occurs through focusing on problems and during the execution. Solving problems in this method is obtained through finding a pattern for increasing organizational perception and understanding and focusing on issues [30]. The relationship between thinking about and focusing on systemic issues and improving the performance of the employees has been proved in a study [31]. Amini et al. conclude that the state of the systemic thinking factor among the majority of managers in the Medical University of Tehran is at a desired level and these managers abide by systemic thinking [32]. Terzic-Supic realized that teaching strategic planning and management plays an effective role in the optimal decision making of hospital managers [33]. Having motivation and being interested in becoming a manager and working in a hospital was another requirement of hospital manager mentioned in some of the interviews. According to the model proposed by the World Health Organization, management qualifications are categorized in three groups including the creation of an empowering and motivating environment which in turn includes guiding and creating motivation in the employees in order to overcome environmental challenges and realize the objectives, ensure the effective utilization of resources, and expanding the level of participation in the whole 
organization and outside the organization [34]. Authorities must pay attention to the point that motivation is one of the main pillars of management [30] and an unmotivated individual cannot be a successful manager in the organization. Therefore, when selecting hospital managers, this issue must be considered and people who are interested and motivated must be prioritized for obtaining the positions of hospital managers. An unmotivated manager can spread this lack of motivation among other employees as well. On the other hand, motivated managers who understand how to motivate employees can work towards realizing the goals of the organization with the help of the employees and they will be successful in performing their other duties as well. In order for the human resource department to have a good performance and be able to select qualified managers for the healthcare system, it should have a qualified manager as well [35]. Therefore, it is suggested that selecting managers be based on a comprehensive and long-term evaluation of the individuals and in this regard, measures such as having human relations, the methods of interacting with colleagues and subordinates, strategic vision, having the power of planning, the strategies of facing problems, and having creativity and initiative must be considered and be the basis of the evaluation. Furthermore, the executive experience and the expertise of the managers must also be considered and it is obvious that those managers must be selected that have an educational background in the fields related to hospital management since the results of the study show that hospital management students who spend a longer time in their hospital will be more familiar with the system an $d$ the requirements and the needs of the institute [19]. The results from Ahmad and Romdhane show that one of the challenges facing hospital managers is the rapid changes in the policies of the Ministry of Health. In other words, when a new minister is appointed, new policies are devised based on the new priorities and plans of the minister and resources are allocated for implementing these policies and operational plans are rapidly executed, and in effect, some of the previous systems become out of order or there is no sufficient opportunity for implementing those systems. The problem of lack of political and managerial stability is observed in the majority of developing countries. Examples include Syria and Tunisia [36, 37]. Also, the effects of the political climate on health policies in Pakistan show that the rapid change of the governments affects the policies, causing the imperfect implementation of various policies [38]. Furthermore, the same problem was experienced in India where in specific time periods, policies are seriously implemented only to stop or slow down in the near future because of financial problems and the low implementation capacity of the healthcare system [39]. As we know, the field of macro policy making and decision making directly depends on the quality of human resources in terms of their knowledge and behavior. Naturally, the higher the qualifications and quality of the individuals, the higher the quality and effectiveness of the decisions. It is obvious that when a deep and informed strategic plan is implemented for each of the policies and plans, we can hope to reduce the effects of personal tastes and ensure their continued implementation after another authority is appointed. One of the challenges mentioned by the interviewees was the shortage of financial and human resources. Based on the results of the study by Delgoshaie and Campbell the shortage of financial resources is one of the operating challenges for hospital programs, which is in line with the results of the current study [41, 42]. A number lower than the standard threshold determined by the Ministry of Health for the human resources in hospitals has been reported in many studies [43, 44]. The results obtained from studies MohebbiFar, Askari, Mehrolhasani evaluating the efficiency of hospitals 
show that one of the factors influencing the lack of efficiency in hospitals is the large number of human resources in hospitals, particularly academic hospitals, which is not in line with the results of the current study [45-47]. It seems that the type of the study may have affected the variation in the results. One of the limitations of this study was the delay in performing some of the interviews and the researchers did their best to get timely and enough time from the interviewees.

\section{Conclusion}

The skills of human relations, strategic vision, and perception as well as work experience and personal characteristics are among the skills required for hospital managers. Due to their nature and their difference with the other service sections, hospitals and their management are much more sensitive. In this regard, the role of the hospital manager is very important, therefore in order to meet the satisfaction of individuals receiving the services and improve the health of community members, which is one of the goals of the healthcare system, as well as to ensure the efficiency and productivity of healthcare resources, decision makers an d policy makers working on selection and appointment of hospital managers must think twice and in this regard, evaluate this group in terms of the capabilities and skills required for the job of hospital management.

\section{Abbreviations}

MSR

Managers Skills Required; QS:Qualitative Study

\section{Declarations}

\section{Acknowledgments}

The researchers would like to thank the Clinical Research Development Unit of the Educational Treatment Center of Imam Reza (PBUH).

\section{Authors'contributions}

FM and JA conceived and designed the study and finalized themethodology and tools used. NB, AS, and AZ collected the data andanalyzed and drafted the manuscript. All the authors made significantcontributions in the manuscript writing and finalizing of the manuscript. Thefinal manuscript has been read and approved by all the authors.

\section{Funding}


No funding.

\section{Availability of data and materials}

Authors report that the data supporting their findings can be publicly shared.

\section{Ethics approval and consent to participate}

This study sought ethical permission attained from the ethics committee of the university. The authors assured respondents that all information collected from this study would remain strictly confidential. All the research procedures in this study followed the ethical standards of the university research and ethics committee. The respondents of this study provided their consent to participate in the research and they actively involved in the survey.

\section{Consent for publication}

Not applicable.

\section{Competing interests}

The authors declare that they have no competing interests

\section{Author details}

${ }^{1}$ Life Style Modification Research Center, Imam Reza Hospital, Kermanshah University of Medical Sciences, Kermanshah, Iran. ${ }^{2} \mathrm{PhD}$ Student of Health Education and Health Promotion, Health Institute, Kermanshah University of Medical Sciences, Kermanshah, Iran. ${ }^{3}$ Shanghai Jiao Tong University, Shanghai, China.

\section{References}

1. Hamidi Y, Eivazi Z. The relationships among employees' job stress, job satisfaction, and the organizational performance of Hamadan urban health centers. Soc Behav Personality Int J. 2010;38(7):963-8. 
2. Supic ZT, Bjegovic V, Marinkovic J, Milicevic MS, Vasic V. Hospital management training and improvement in managerial skills: Serbian experience. Health Policy. 2010;96(1):80-9.

3. Kiaei M, Salari M, Moradi R. Assessment of effective management skills in managers of teaching hospitals in Qazvin University of Medical Sciences 2013.

4. EM WR. Improving hospital performance in the Eastern mediterranea Region morocco: Word Health organization. 2009 [cited 20154 December].

5. Barati O, Sadeghi A, Khammarnia M, Siavashi E, Oskrochi G. A Qualitative Study to Identify Skills and Competency Required for Hospital Managers. Electronic Physician. 2016;8(6):2458.

6. Fang C-H, Chang S-T, Chen G-L. Competency development among Taiwanese healthcare middle manager: A test of the AHP approach. African J Business Manag. 2010;4(13):2845-55.

7. Lin Y-J, Yu-Wen P-S, Sheng-JoWang L, Li A-T, editors. Constructing Executive-level Health Manager's Competency Model- A Case Study of the Health Examination Center at a Teaching Hospital in Central Taiwan. 2nd International Conference on Education and Management Technology IPEDR; 2011.

8. Battilana J, Gilmartin M, Sengul M, Pache A-C, Alexander JA. Leadership competencies for implementing planned organizational change. leadership Q. 2010;21(3):422-38.

9. Dignam D, Duffield C, Stasa H, Gray J, Jackson D, Daly J. Management and leadership in nursing: an Australian educational perspective. J Nurs Manag. 2012;20(1):65-71.

10. Müller R, Turner R. Leadership competency profiles of successful project managers. Int J Project Manag. 2010;28(5):437-48.

11. Crawford L, Nahmias AH. Competencies for managing change. Int J Project Manag. 2010;28(4):40512.

12. Etal LNH. Need Assessment on Managerial Competency Development at Provincial and District Hospitals. MINISTRY OF HEALTH Department of Financing and Planning. Hanoi. 2010.

13. Pillay R. The skills gap in hospital management: a comparative analysis of hospital managers in the public and private sectors in South Africa. J Health Manag. 2010;12(1):1-18.

14. Majid NA, Jelas ZM, Azman N, Rahman S. Communication skills and work motivation amongst expert teachers. Proc-Soc Behav Sci. 2010;7:565-7.

15. Ahan CM, Zohour PV. the Relationship Between Managers'Managarial Knowledge and Organizational Effectiveness and Well-Being of High Schools in Mashhad. 2009.

16. LK C. Nurse manager competencies. The University of lowa2010.

17. MacKinnon NJ, Chow C, Kennedy PL, Persaud DD, Metge CJ, Sketris I, editors. Management competencies for Canadian health executives: views from the field. Healthcare Management Forum; 2004: SAGE Publications Sage CA: Los Angeles, CA.

18. Keshtkaran A, Heidari A, Bastani P. Study of managers' communication skills based on the staff's view in Shiraz University Of Medical Sciences. J Payavard Salamat. 2012;5(4):41-8. 
19. Khadka DK, Gurung M, Chaulagain N. Managerial competencies-A survey of hospital managers' working in Kathmandu valley, Nepal. J Hospital Admin. 2014;3(1):62-72.

20. Stefl ME. Common competencies for all healthcare managers: the Healthcare Leadership Alliance model. J health manag. 2008;53(6): 360-73.

21. Kalargyrou V, Pescosolido AT, Kalargiros EA. Leadership Skills in Management Education. Academy Educ Leadership J. 2012;16(4): 12-19.

22. AbuAIRub RF, AL-ZARU IM. Job stress, recognition, job performance and intention to stay at work among Jordanian hospital nurses J Nurs Manag. 2008;16(3):227-36.

23. Erkutlu HV, Chafra J. Relationship between leadership power bases and job stress of subordinates: example from boutique hotels. Manag Res News. 2006;29(5):285-97.

24. Salami A, Ojokuku R, Ilesanmi O. Impact of job stress on managers' performance. European J Sci Res. 2010;45(2):249-60.

25. Griffin ML. Gender and stress: A comparative assessment of sources of stress among correctional officers. J Contem Crim Justice. 2006;22(1):5-25.

26. Kebede S, Mantopoulos J, Ramanadhan S, Cherlin E, Gebeyehu M, Lawson R, et al. Educating leaders in hospital management: a pre-post study in Ethiopian hospitals. Glob Public health. 2012;7(2):16474.

27. Zarei E, Farzianpour F, Pouragha B, Abbasi Borogeni P, Mohammadzadeh M. Managers' Development Needs Assessment: Perspective of Middle Managers of Public Hospitals of Tehran. J Hospital. 2014;13(2):29-36.

28. Rivkani F. Assessment of required management information of hospital managers of ministry of health and medical education in Tehran in 2000 [Thesis]. Tehran, Iran: Tehran University of Medical Sciences. 2001.

29. M. Organization and management: research approach. Tehran, Iran: Termeh Publications; 2011.

30. Mortazavi S, Nazmi S, Jafaryani H. Relationship between strategic thinking and performance [Thesis in Persian]. Mashhad: Ferdosi University. 2008.

31. Aghaye T JM, Mirmohammadali S. Systemic thinking and Improving staff performance. J Busin Manag.11(3):156-79.

32. Amini MT, Bakhtiari L, Dargahi H, Karimi O, Moammai H, Janbozorgi M, et al. Measurement of systemic thinking among TUMS senior managers using Goldman strategic model. J Payavard Salamat. 2013;7(3):188-96.

33. Terzic-Supic Z, Bjegovic-Mikanovic V, Vukovic D, Santric-Milicevic M, Marinkovic J, Vasic V, et al. Training hospital managers for strategic planning and management: a prospective study. BMC Med Educ. 2015;15(1):25.

34. Model Wgc. . World Health Organization; Management for healthservicesdelivery. 2010.

35. Filerman G. Closing the management competence gap. Hum Res Health. 2003;1(1):7. 
36. Ahmad B, Fouad FM, Elias M, Zaman S, Phillimore P, Maziak W. Health system challenges for the management of cardiovascular disease and diabetes: an empirical qualitative study from Syria. Int $\mathrm{J}$ Public Health. 2015;60(1):55-62.

37. Romdhane HB, Tlili F, Skhiri A, Zaman S, Phillimore P. Health system challenges of NCDs in Tunisia. Int J Public Health. 2015;60(1):39-46.

38. Khan MM VdHW. Health Policy Analysis: The Case of Pakistan. Printed in the Netherlands by Datawyse Maastricht. 2006.

39. Siegel K, Narayan K, Kinra S. Finding a policy solution to India's diabetes Health Affairs. 2008;27(4):1077-90.

40. Ziari A, Abachizade K, Rassouli M, Mohseny M. Assessment of barriers of implementation of clinical governance in educational hospitals of Shahid Beheshti University of Medical sciences: A qualitative study. J Hospit. 2015;13(4):93-103.

41. Delgoshaie $B$, Tabibi J, Pahlavan P. The model of improving human resource in Iran's health system. Res Med J. 2010;31(4):317-25.

42. Campbell S, Sheaff R, Sibbald B, Marshall M, Pickard S, Gask L, et al. Implementing clinical governance in English primary care groups/trusts: reconciling quality improvement and quality assurance. BMJ Q Safety. 2002;11(1):9-14.

43. Sadeghi far J PA, Ahmadi B, Zeraati H, Arab M. Assessment of human resource needs in llaam university of medical sciences hospitals. . Scholarly J Ilaam Univ Med Sci. 2011;19(1):24-31.

44. Farajzadeh Z, Nakhaee M, Tabiee Sh NA. Pejmankhah Sh. The study of number and structure of nursing personnels in Birjand University of medical sciences Scholarly J Nurs Mid, Birjand Univ Med Sci. 2006;3(3):4.

45. MohebbiFar R GGRH. Technical efficiency in hospitals. J Guilan Univ Med Sci. 2014;88(22): 73-9.

46. Askari R, Goudarzi R, Fallahzadeh H, Zarei B, Dehqani Tafti A. Efficiency appraisal of Yazd university of medical science hospitals by quantitative approach data envelopment analysis (DEA). J Payavard Salamat. 2012;6(3):215-24.

47. Mehrolhasani M, Yazdi Feyzabadi V, Barfeh Shahrbabak T. Assessing performance of Kerman provinces hospitals using pabon lasso diagram between 2008 and 2010. J Hospit. 2014;12(4):99108. 